\title{
Pengembangan LKS pada Materi Cahaya dan Alat Optik dengan Model Inquiry Berbasis Karakter untuk Siswa SMP
}

\author{
Yasinta Embu Ika ${ }^{1 *}$, Ana Silfiani Rahmawati ${ }^{2}$ \\ 1,2 Program Studi Pendidikan Fisika, FKIP - Universitas Flores. \\ JI. Sam Ratulangi No. XX, Ende, Nusa Tenggara Timur 86317 Indonesia. \\ *Email: sinta83ika@gmail.com
}

\begin{abstract}
Abstrak
Penelitian ini bertujuan untuk mengetahui pengaruh pengembangan LKS cahaya dan alat optik model inquiry bebasis karakter untuk siswa SMP. Penelitian ini menggunakan jenis Research dan Development (R\&D) dengan Quasi Experimental Design berbentuk Nonequivalent Control Group Design. Hasil penelitian menunjukkan: bahwa LKS cahaya dan alat optik model inquiry berbasis berkarakter termasuk dalam kriteria sangat layak digunakan sebagai panduan belajar siswa kelas VIII SMP dengan presentasi kelayakan LKS sebesar 96,87\%; Terdapat perbedaan yang signifikan antara hasil belajar siswa yang menggunakan LKS IPA (fisika) berkarakter model inquiry dengan siswa yang tidak menggunakan LKS IPA (fisika) berkarakter model inquiry; Penerapan LKS IPA (fisika) berkarakter dengan model inquiry dapat meningkatkan pemahaman siswa pada materi pokok cahaya dan alat optik. Peningkatan hasil belajar aspek kognitif termasuk pada kriteria sedang; dan Penggunaan LKS LKS cahaya dan Alat Optik berkarakter dengan model inquiry dapat mengembangkan karakter siswa yaitu berada pada kriteria membudaya.
\end{abstract}

Kata kunci: Model inquiry, karakter, LKS Cahaya dan Alat Optik.

\begin{abstract}
This research aims to investigate the effect of developing character-based phisic based character inquiry models for junior high school students. This research used the type of Research and Development (R\&D) with Quasi Experimental Design in the form of Nonequivalent Control Group Design. The results show: worksheet light and optical instruments based on inquiry models are included in the criteria are very suitable to be used as a study guide for students of class VIII SMP witha presentation on the feasibilityof the worksheet 96,87\%; There is a significant difference between the learning outcomes of students who use the Science worksheet light and optical inquiry model character and students who do not use Science worksheet light and optical inquiry model character; The application of the Natural Science worksheet light and optical characterized by the inquiry model can improve students' understanding of the subject matter of light and optical devices. Improved learning outcomes cognitive aspects including the criteria are; and The use of science worksheets light and optical characterized by inquiry models can develop student character that is within the criteria of culture.
\end{abstract}

Keywords: Inquiry Model, character, light and optical devices worksheet.

\section{PENDAHULUAN}

LKS fisika merupakan salah satu perangkat pembelajaran yang wajib digunakan dalam kegiatan pembelajaran fisika. Hal ini dikarenakan mata pelajaran sains (IPA) pada hakikatnya terdiri dari lima unsur (Kemendikbud, 2014 dan Puskur, 2017) yaitu: (a) sikap: rasa ingin tahu tentang benda, fenomena alam serta hubungan sebab akibat yang menimbulkan masalah baru dapat dipecahkan dengan prosedur yang benar; (b) proses: prosedur pemecahan masalah melalui metode ilmiah; (c) produk: berupa fakta, prinsip, teori dan hukum; (d) aplikasi: penerapan metode ilmiah dan konsep fisika dalam kehidupan sehari-hari; (e) Evaluasi: hasil dari ilmu pengetahuan lebih diperuntukkan bagi kesejahteraan umat manusia serta segala 
makhluk hidup di muka bumi. Berdasarkan lima unsur tersebut, pada unsur kedua yaitu proses, terdapat metode ilmiah yang dapat dilakukan dengan menggunakan perangkat LKS. LKS merupakan salah satu sumber belajar, yakni segala sesuatu yang memudahkan siswa memperoleh sejumlah informasi pengetahuan, pengalaman dan keterampilan dalam proses pembelajaran.

LKS berbasis karakter diharapkan memberikan sumbangan tidak langsung pada pembentukan Sumber Daya Manusia (SDM) yang berkualitas. SDM yang demikian adalah SDM yang beretika, bermoral, dan sopan santun. Mereka akan menjadi generasi penerus bangsa yang berkarakter dan berkualitas akhlaknya sekaligus cerdas intelektualnya. Banyak contoh anak didik yang cerdas, tetapi kualitas akhlaknya kurang baik, maka mereka tidak dapat diharapkan untuk menjadi generasi penerus yang dapat membangun bangsa kita (Kemendiknas, 2011).

Perlu dikembangkan sebuah LKS berkarakter yang dapat melatih siswa untuk bertindak dan berpikir seperti seorang ilmuwan dalam menyelesaikan suatu persoalan atau masalah. Pendapat yang dikemukakan oleh Salis (2016: 7), siswa diarahkan untuk membuat kesimpulan tentatif yang menjadikan kegiatan belajar lebih menyerupai kegiatan penelitian yang biasa dilakukan para ahli. Dalam mempelajari suatu konsep fisika, siswa perlu dilatih untuk mengikuti tahapan-tahapan penyelidikan secara utuh, sehingga pemahaman siswa menjadi lebih lengkap dan bukan sekedar menghafal rumus dan konsepkonsep fisika. LKS berkarakter yang dapat dikembangkan yaitu LKS dengan model inquiry.

Pembelajaran inquiry menurut Kinsdsvatter adalah model pengajaran di mana guru melibatkan kemampuan berpikir kristis siswa untuk menganalisis dan memecahkan persoalan secara sistematik (Suparno, 2007). Secara sederhana langkah-langkah atau proses inquiry antara lain; identifikasi masalah, identifikasi variabel, membuat hipotesis, merencanakan penyelidikan, melaksanakan penyelidikan, mengumpulkan data, menyajikan data, interpretasi data, dan menarik kesimpulan. Langkah-langkah ini merupakan ciri metode ilmiah atau disebut pendekatan ilmiah.

Model pembelajaran inquiry sangat baik digunakan karena mampu mendorong siswa untuk mengonstruksi pengetahuan baik yang berupa konsep, teori, maupun pemecahan masalah secara bermakna (Salis, 2016:9). Siswa melakukan kegiatan yang menantang untuk menyelesaikan permasalahan yang dihadapi melalui penyelidikan ilmiah yang dapat dipertanggung jawabkan. Dalam Permendiknas (2006) ditegaskan bahwa metode ilmiah sebagai bagian pokok dalam inquiry perlu diterapkan secara terintegrasi di kelas. National Research Science Council (NRSC, 2000) juga menekankan agar semua pendidik dalam bidang sains untuk menerapkan model pembelajaran inquiry dalam kegiatan pembelajaran bidang sains, karena dengan inquiry bisa meningkatkan kemampuan pemecahan masalah.

Model inkuiri merupakan salah satu model pembelajaran yang berorientasi pada pembelajaran berpusat pada siswa (Student Center Learning). Suyanto (2006: 11) berpendapat bahwa esensi dari model pembelajaran inkuiri adalah untuk melibatkan siswa dalam masalah yang sesungguhnya dengan cara memberikan tantangan kepada suatu penyelidikan, membantu mereka untuk mengidentifikasi suatu masalah secara konseptual atau bersifat metodologis, dan merekayasa mereka untuk merancang cara pemecahan masalah tersebut. Menurut standar isi Permendiknas nomor 22 tahun 2006, pembelajaran inquiry digunakan dalam pembelajaran fisika, karena dapat mengembangkan kemampuan siswa untuk memahami dan memperoleh pengetahuan melalui cara berpikir sistematis dan ilmiah. Ditegaskan juga dalam (NRC, 1996), bahwa berpikir ilmiah dalam inquiry meliputi kegiatankegiatan; mengobservasi, merumuskan pertanyaan yang relevan, merencanakan penyelidikan atau investigasi, mereview apa yang telah diketahui, melaksanakan percobaan atau eksperimen dengan menggunakan alat untuk memperoleh data, menganalisis dan menginterpretasi data, serta membuat prediksi 
dan mengkomunikasikan hasilnya.

Tujuan penelitian ini adalah; a) untuk mengetahui tingkat kelayakan LKS fisika berkarakter dengan model inkuiri; b) untuk mengetahui perbedaan hasil belajar siswa yang menggunakan LKS fisika berkarakter model inquiry dengan siswa yang tidak menggunakan LKS fisika berkarakter model inquiry; c) untuk mengetahui pemahaman siswa setelah diberikan LKS fisika berkarakter dengan model inquiry; d) untuk mengetahui perkembangan karakter siswa.

\section{METODE/EKSPERIMEN}

Penelitian ini menggunakan jenis penelitian Research and Development dengan Quasi Experimental Design berbentuk Nonequivalent Control Group Design. Desain penelitian ini menggunakan kelas eksperimen dan kelas kontrol yang tidak dipilih secara random (Sugiyono, 2010: 116).

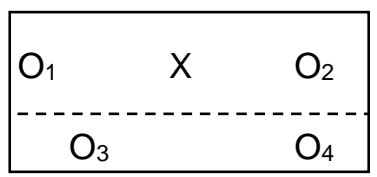

Keterangan:

$\mathrm{O}_{1}=$ nilai pre-test kelas eksperimen

$\mathrm{O}_{2}=$ nilai post-test kelas ekperimen

$\mathrm{O}_{3}=$ nilai pre-test kelas kontrol

$\mathrm{O}_{4}=$ nilai post-test kelas kontrol

$\mathrm{X}=$ pembelajaran menggunakan LKS IPA

(fisika) terintegrasi karakter dengan model inquiry.

Penelitian dilaksanakan selama bulan April-Mey 2019. Populasi adalah siswa kelas VIII tahun ajaran 2018/2019. Sampel penelitian ini berjumlah 67 orang siswa yang terdiri dari 33 orang kelas eksperimen dan 34 orang kelas kontrol. Teknik pengambilan sampel adalah purporsive sampling yaitu penentuan sampel karena beberapa pertimbangan seperti penyesuaian materi dengan kondisi lapangan, dan jadwal pertemuan yang harus disesuaikan dengan jadwal sekolah.

Penelitian ini mencakup tiga tahap, yaitu define atau studi pendahuluan, design atau rancangan, dan develop atau pengembangan.
Tahapan yang dilakukan pada penelitian ini dapat dirinci seperti berikut.

1. Tahap Define

Studi pendahuluan merupakan tahap persiapan sebelum penelitian.

2. Tahap Design

Tahap rancangan dalam penelitian ini dimulai dengan menyusun materi sesuai kurikulum. Setelah itu, menyusun LKS dengan model inkuiri. LKS disusun dengan mengacu pada kurikulum dan disisipi dengan pendidikan karakter melalui petunjuk dan langkah kerja, tujuan serta indikator keberhasilan.

3. Tahap Develop

a) Validasi Pakar

LKS fisika terintegrasi karakter dengan metode inkuiri yang telah disusun divalidasi oleh pakar. Hasil penilaian validator digunakan sebagai perbaikan dan penyempurnaan produk sebelum diuji cobakan.

b) Uji Coba Skala Kecil

Uji coba skala kecil LKS fisika terdiri dari uji keterbacaan dan uji kelayakan. Uji keterbacaan menggunakan tes rumpang yang dilakukan pada siswa, bertujuan untuk mengetahui bahwa LKS mudah dipahami atau tidak. Uji kelayakan dilakukan pada guru fisika yang bertujuan untuk mengetahui kelayakan LKS.

c) Uji Coba Skala Besar

Uji coba skala besar dilakukan setelah melakukan perbaikan LKS berdasarkan hasil uji coba skala kecil. Pada uji coba skala besar, siswa mendapatkan pembelajaran berpanduan LKS.

Metode pengumpulan data yang digunakan dalam penelitian ini yaitu metode tes, kuisioner dan dokumentasi. 1) Metode tes yang digunakan dalam penelitian ini adalah tes tertulis dalam bentuk pilihan ganda. Tes pilihan ganda dilakukan untuk mengetahui perubahan tingkat penguasaan siswa menggunakan LKS; 2) Metode Kuisioner digunakan untuk mengetahui tingkat kelayakan LKS dan 
perkembangan karakter siswa setelah menggunakan LKS. Instrumen kuisioner adalah angket; dan 3) Metode dokumentasi digunakan untuk mendapatkan dokumen atau data-data yang mendukung penelitian, yaitu daftar nama siswa, data guru yang menjadi reviewer kelayakan LKS, dan foto pelaksanaan penelitian.

Data yang diperoleh berupa hasil validasi tes hasil belajar kognitif siswa, kelayakan dan keterbacaan LKS fisika berkarakter dengan model inquiry, peningkatan hasil belajar siswa dan perkembangan karakter siswa selama pembelajaran di kelas. Data hasil kelayakan LKS fisika dan respon siswa dianalisis secara deskriptif kualitatif dengan persentase. Sementara, untuk melihat peningkatan hasil belajar siswa dianalisis menggunakan uji homogenitas, uji-t dan uji gain dan data perkembangan karakter siswa dihitung dengan mencari persentase.

\section{HASIL DAN PEMBAHASAN}

\section{HASIL}

\section{Hasil Belajar Kognitif}

Sebelum dilakukannya perlakuan atau tindakan penelitian, peneliti melakukan validasi tes hasil belajar. Validasi tes hasil belajar siswa dengan materi cahaya dan alat optik secara keseluruhan berkategori valid. Tes tersebut diuji coba pada kelas IX dan hasilnya menunjukkan bahwa tes hasil belajar yang dikembangkan layak digunakan dalam pembelajaran fisika.

Hasil belajar kognitif didapat melalui tes tertulis. Tes tertulis dilaksanakan sebelum dan setelah melakukan pembelajaran menggunakan LKS fisika berkarakter dengan metode inkuiri. Hasil belajar kognitif dianalisis menggunakan uji gain dan uji-t. Uji gain digunakan untuk mengetahui signifikansi peningkatan hasil belajar. Berikut disajikan hasil uji gain berupa ratarata hasil belajar kognitif siswa.

Tabel 1. Rerata Hasil Belajar Kognitif Siswa

\begin{tabular}{rll|l|l}
\hline No & Kelas & Pretes & Posttes & Kriteria \\
& Eksperi & 48,03 & 66,25 & Sedang \\
1 & men & 4 Senatan \\
2 & Kontrol & 43,24 & 43,68 & Rendah \\
\hline
\end{tabular}

Selain itu, juga disajikan hasil uji $\mathrm{t}$ berupa perbandingan hasil belajar kognitif siswa.

Tabel 2. Perbandingan hasil belajar kognitif siswa

\begin{tabular}{cc|c} 
Variabel & Kls. eksperimen & Kls. kontrol \\
Rerata & 66,52 & 43,68 \\
S.deviasi & 10,04 & 12,75 \\
Varians & 100,76 & 162,61 \\
Sampel & 33 & 34 \\
\hline
\end{tabular}

\section{Kelayakan LKS}

Validasi LKS fisika secara keseluruhan berkategori valid. Hasil tersebut menunjukkan bahwa LKS yang dikembangkan layak digunakan dalam pembelajaran. Selanjutnya dilakukan uji coba skala kecil terdiri dari uji keterbacaan dan uji kelayakan. Uji keterbacaan diberikan pada 10 orang siswa, untuk mengetahui apakah LKS mudah dipahami atau tidak. Hasil analisis uji keterbacaan menunjukkan bahwa LKS mudah dipahami oleh siswa. Sedangkan Uji kelayakan diberikan pada 4 guru IPA (fisika) yang bertujuan untuk mengetahui bahwa LKS layak atau tidak digunakan sebagai panduan pembelajaran. Dari hasil analisis data, presentasi kelayakan LKS sebesar $96,87 \%$ dari 3 komponen dan 14 total indikator yang dikembangkan, artinya LKS IPA (fisika) berbasis karakter dengan model inquiry pada materi cahaya dan alat optik yang dihasilkan termasuk dalam kriteria sangat layak. Hasil analisis dapat dilihat pada Tabel 3.

Tabel 3. Analisis Kelayakan LKS

\begin{tabular}{|c|c|c|c|c|}
\hline \multirow[b]{2}{*}{ No } & \multirow[b]{2}{*}{ Responden } & \multicolumn{3}{|c|}{ Aspek yang dinilai } \\
\hline & & (1) & (2) & (3) \\
\hline 1 & $\mathrm{~A} 01$ & 3,85 & 3,70 & 4,00 \\
\hline 2 & A02 & 4,00 & 3,80 & 3,90 \\
\hline 3 & $\mathrm{~A} 03$ & 3,90 & 3,80 & 3,95 \\
\hline 4 & $\mathrm{~A} 04$ & 3,80 & 3,80 & 4,00 \\
\hline 5 & Rerata skor & 3,88 & 3,77 & 3,96 \\
\hline 6 & Presentasi & 97,18 & 94,37 & 99,06 \\
\hline 7 & Kategori & $\begin{array}{l}\text { Sangat } \\
\text { layak }\end{array}$ & $\begin{array}{l}\text { Sangat } \\
\text { layak }\end{array}$ & $\begin{array}{l}\text { Sangat } \\
\text { layak }\end{array}$ \\
\hline \multirow{2}{*}{\multicolumn{2}{|c|}{$\begin{array}{c}\text { Rata-rata } \\
\text { presentasi } \\
\text { Kriteria }\end{array}$}} & \multicolumn{3}{|c|}{96,87} \\
\hline & & \multicolumn{3}{|c|}{ Sangat layak } \\
\hline
\end{tabular}

Keterangan:
(1) : kelayakan
(2) : bahasa
(3) : penulisan 


\section{PEMBAHASAN}

\section{Hasil Belajar Kognitif}

Hasil belajar kognitif didapat melalui tes tertulis. Tes tertulis dilaksanakan sebelum dan setelah melakukan pembelajaran menggunakan LKS fisika berkarakter dengan metode inquiry. Hasil belajar kognitif dianalis menggunakan uji gain dan uji-t. Uji gain digunakan untuk mengetahui signifikansi peningkatan hasil belajar. Uji-t digunakan untuk mengetahui perbedaan rata-rata hasil belajar sebelum dan setelah pembelajaran menggunakan LKS. Hasil post-test kedua kelas diuji perbedaan dua rata-rata menunjukkan bahwa kelas eksperimen lebih baik dari kelas kontrol. Hasil belajar kognitif siswa disajikan pada tabel 4 dan 5 dibawah ini.

Tabel 4. Rerata Hasil Belajar Kognitif Siswa

\begin{tabular}{rll|l|l}
\hline No & Kelas & Pretes & Posttes & $\begin{array}{l}\text { Kriteria } \\
\text { Peningkatan }\end{array}$ \\
& Eksperi & 48,03 & 66,25 & Sedang \\
1 & men & 4,03 & & \\
2 & Kontrol & 43,24 & 43,68 & Rendah \\
\hline
\end{tabular}

Berikut ini disajikan kisaran nilai atau hasil belajar siswa yang terekam dalam nilai terendah dan nilai tertinggi pada kelas eksperimen dan kelas kontrol.

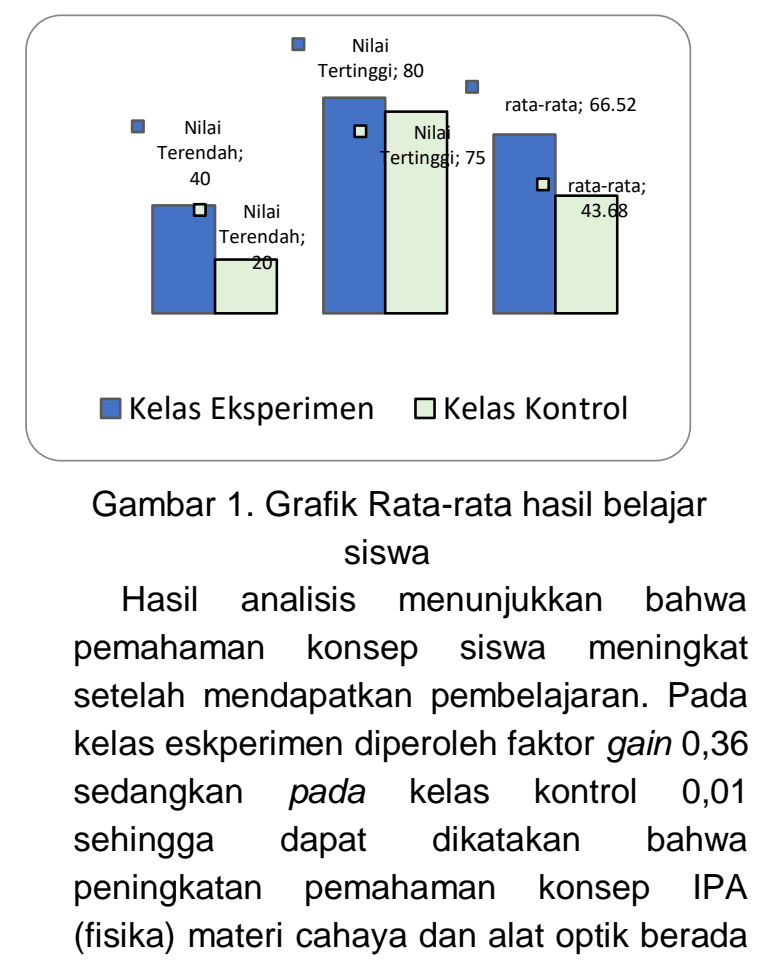

pada kriteria sedang untuk kelas eksperimen, dan kriteria rendah untuk kelas kontrol. Berdasarkan analisis tersebut dapat disimpulkan bahwa pemahaman konsep siswa kelas eksperimen lebih tinggi dibandingkan siswa kelas kontrol. Hal ini sejalan dengan hasil penelitian oleh Budimah \& Rosidin (2014) yang menunjukkan bahwa penggunaan media pembelajaran LKS mempengaruhi naiknya prestasi belajar siswa. Standar deviasi nilai post-test siswa kelas eksperimen dan kelas kontrol sebesar 10,04 dan 12,75. Perbandingan hasil belajar kognitif setelah menggunakan LKS fisika berkarakter model inquiry dengan LKS konvensional disajikan pada tabel 5 .

Tabel 5. Perbandingan hasil belajar kognitif siswa

\begin{tabular}{cc|c}
\hline Variabel & Kls. eksperimen & Kls. kontrol \\
Rerata & 66,52 & 43,68 \\
S.deviasi & 10,04 & 12,75 \\
Varians & 100,76 & 162,61 \\
Sampel & 33 & 34 \\
\hline
\end{tabular}

Perbandingan hasil belajar kognitif siswa di atas dapat pula disajikan dalam bentuk grafik di bawah ini:

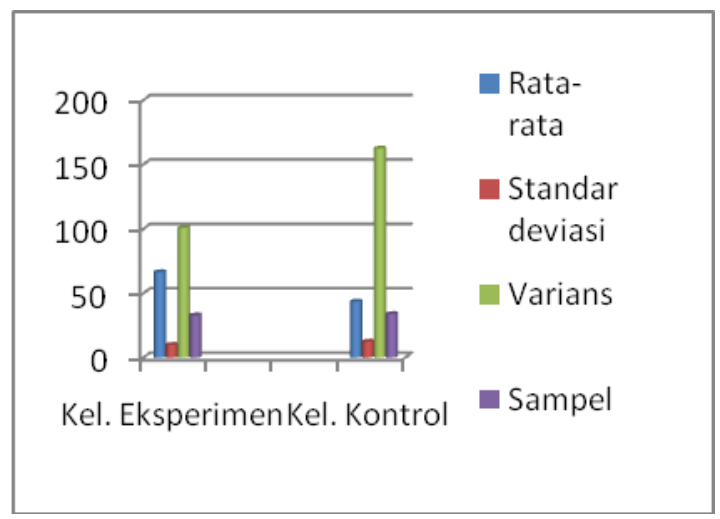

Gambar 2. Grafik Perbandingan hasil belajar kognitif siswa

Berdasarkan hasil analisis uji-t menunjukkan bahwa terdapat perbedaan yang signifikan antara hasil belajar kelas eksperimen dan hasil belajar kelas kontrol. Dari perbedaan hasil belajar menunjukkan bahwa LKS fisika berkarakter dengan model inquiry efektif digunakan sebagai panduan belajar fisika pada siswa kelas VIII. Adanya perbedaan peningkatan hasil belajar yaitu 
karena pembelajaran dilakukan melalui suatu penyelidikan ilmiah, dimana siswa dapat mengalami sendiri suatu proses kerja ilmiah yang meliputi; siswa memberikan jawaban sementara dari suatu persoalan yang akan diselidiki, siswa dapat merencanakan penyelidikan, mengambil data, mengolah data, dan menarik kesimpulan. Hal ini sesuai hasil penelitian oleh Yıldırım, Kurt, \& Ayas. (2011) mengatakan bahwa LKS lebih efektif meningkatkan hasil belajar sekaligus membantu siswa memperoleh keterampilan proses ilmiah seperti melakukan percobaan, mencatat serta menganalisa data, dan sebagainya. Selain itu, hasil belajar siswa meningkat karena pengintegrasian karakter pada LKS yang dikembangkan, hal ini sesuai pendapat Benninga et al. (2003) yang menyatakan bahwa pengintegrasian karakter memberi pengaruh positif terhadap peningkatan hasil belajar.

\section{Kelayakan LKS}

Tahapan pengembangan LKS IPA (fisika) berkarakter dengan model inquiry yang telah disusun, diawali dengan validasi ahli (kolega), kemudian dilanjutkan dengan uji coba skala kecil, dan tahap akhir uji skala besar. Dari hasil validasi ahli menunjukkan bahwa presentasi kelayakan LKS sebesar 95,83\%. Namun terdapat beberapa bagian yang perlu diperbaiki, seperti: pada bagian isi LKS, pada setiap tahapan perlu ditambahkan keterangan berupa penjelasan singkat mengenai kegiatan yang akan dilakukan siswa, agar siswa lebih fokus pada tujuan yang akan dicapai. Selanjutnya pada bagian permasalahan, sebaiknya permasalahan yang akan diajukan sudah disiapkan oleh guru agar sasaran penyelidikan tidak membias terlalu jauh.

Setelah dilakukan revisi, lalu dilanjutkan dengan uji coba skala kecil. Uji coba skala kecil terdiri dari uji keterbacaan dan uji kelayakan. Uji keterbacaan diberikan pada 16 orang siswa, untuk mengetahui apakah LKS mudah dipahami atau tidak. Hasil analisis uji keterbacaan menunjukkan bahwa LKS mudah dipahami oleh siswa.
Sedangkan Uji kelayakan diberikan pada 4 guru IPA (fisika) yang bertujuan untuk mengetahui bahwa LKS layak atau tidak digunakan sebagai panduan pembelajaran.

Dari hasil analisis data, presentasi kelayakan LKS sebesar $96,87 \%$ dari 3 komponen dan 14 total indikator yang dikembangkan, artinya LKS IPA (fisika) berbasis karakter dengan model inquiry pada materi rangkaian listrik yang dihasilkan termasuk dalam kriteria sangat layak. Berdasarkan analisis data tersebut menunjukkan analisis kelayakan LKS cahaya dan alat optik dalam kategori sangat layak. Hal ini sejalan dengan penelitian Kaleka, \& Ika (2019) yang menunjukkan bahwa uji kelayakan lembar kerja siswa llmu Pengetahuan Alam berkarakter layak digunakan sebagai panduan pembelajaran ilmu pengetahuan alam.

\section{Perkembangan Nilai Karakter}

Karakter yang dikembangkan dalam penelitian ini adalah rasa ingin tahu, kreatif, jujur, percaya diri, disiplin, dan bertanggung jawab. Data perkembangan karakter didapat melalui angket. Besarnya perkembangan karakter siswa dianalisis menggunakan uji gain. Hasil analisis karakter siswa disajikan pada gambar berikut.

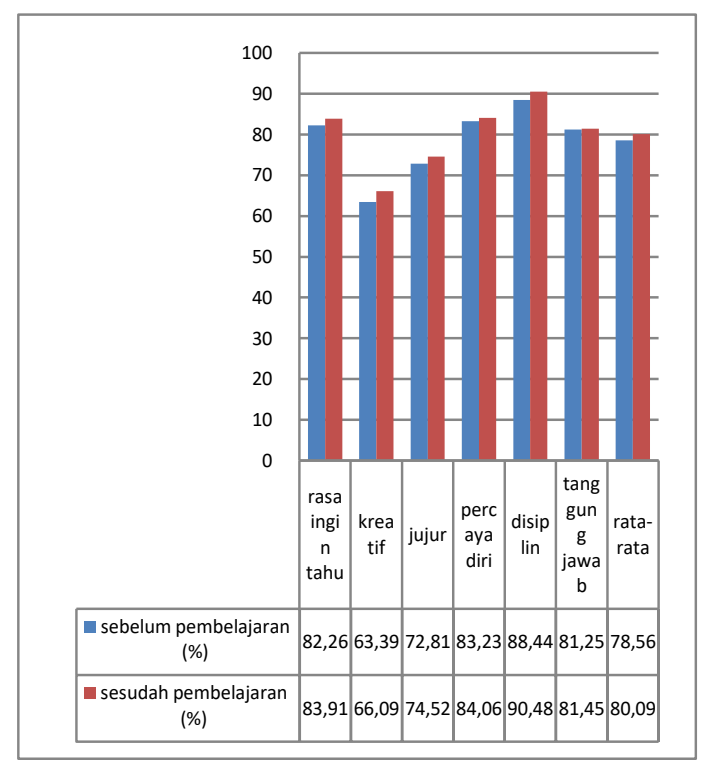

Gambar 4. Rata-rata Perkembangan Karakter Siswa 
Berdasarkan hasil analisis perkembangan karakter secara keseluruhan, terlihat bahwa nilai karakter meningkat dari sebelum pembelajaran (78,56\%) dan setelah pembelajaran $(80,09 \%)$ atau meningkat sebesar $1,53 \%$. Hal ini sejalan dengan penelitian Fauzia, Yulianti, \& Khumaedi (2013) yang menunjukkan bahwa pengembangan LKS Fisika materi suhu dan kalor dapat digunakan sebagai panduan pembelajaran dengan kategori layak atau berada pada kriteria tinggi sehingga mudah dipahami dan dapat digunakan secara mandiri oleh pembaca. LKS juga dapat meningkatkan hasil belajar kognitif dan dapat membangun karakter siswa.

\section{PENUTUP}

\section{SIMPULAN}

Berdasarkan hasil analisis, diskusi, dan pembahasan, maka dapat dibuat kesimpulan bahwa: LKS IPA (fisika) berkarakter dengan model inquiry termasuk dalam kriteria sangat layak digunakan sebagai panduan belajar siswa kelas VIII SMP; Terdapat perbedaan yang signifikan antara hasil belajar siswa yang menggunakan LKS IPA (fisika) berkarakter model inquiry dengan siswa yang tidak mengunakan LKS IPA (fisika) berkarakter model inquiry; Penerapan LKS IPA (fisika) berkarakter dengan model inquiry dapat meningkatkan pemahaman siswa pada materi pokok cahaya dan alat optik. Peningkatan hasil belajar aspek kognitif termasuk pada kriteria sedang; dan Penggunaan LKS IPA (fisika) berkarakter dengan model inquiry dapat mengembangkan karakter siswa yaitu berada pada kriteria membudaya.

\section{SARAN}

Penerapan LKS fisika berkarakter dalam pelaksanaan pembelajaran sudah baik namun guru harus bisa mengelola waktu selama pembelajaran agar pembelajaran bisa berjalan lebih efektif dan efisien. Disarankan penelitipeneliti selanjutnya memberikan gambaran dengan jelas kepada siswa dan guru tentang pembelajaran berbasis karakter, serta LKS yang digunakan pada saat pembelajaran lebih baik dibagikan kepada siswa sebelum pembelajaran dilaksanakan sehingga siswa lebih mudah dalam memahami LKS tersebut.

Pembelajaran menggunakan LKS IPA (fisika) berkarakter dengan model inquiry merupakan hal baru bagi siswa sehingga perlu penjelasan oleh guru sehingga siswa lebih siap. Karakter siswa tidaklah mudah untuk dibentuk dalam waktu yang singkat dan juga sulit untuk diukur. Oleh karena itu diperlukan ketekunan guru dan juga dapat menggunakan 2 atau 3 instrumen sebagai alat ukur karakter siswa.

\section{UCAPAN TERIMAKASIH}

Ucapan terima kasih ditujukan kepada:

1. SMP Negeri 1 Ende yang bersedia sebagai mitra dalam hal penelitian ini yang dibuktikan dengan surat kontrak penelitian, No 198/I 21.27/SMP.1/MN/2019.

2. Badan Kesatuan Bangsa, Politik dan Perlindungan Masyarakat (KESBANGPOLLINMAS) pemerintah Kabupaten Ende yang bersedia memberikan rekomendasi untuk mengadakan penelitian ini yang dibuktikan dengan surat keterangan No. BKPPM. 423/IV/02/IV/2019

3. Lembaga Penelitian dan Pengabdian Kepada Masyarakat Universitas Flores yang bersedia memberikan ijin melakukan penelitian yang dibuktikan denga surat ijin No. 36/115/F12/N/2019

4. DPRM Dikti tahun anggaran 2019 yang bersedia mendanai penelitian ini yang dibuktikan dengan surat kontrak penelitian antara ketua LPPM Universitas Flores dengan ketua pelaksana penelitian dosen pemula No. 72/115/F12/N/2019

5. Ibu Safridayati Meynar sebagai guru mata pelajaran IPA Fisika SMPN 1 Ende yang bersedia membantu peneliti dalam pelaksanaan penelitian ini.

\section{REFERENSI}

Benninga, J. S., Berkowitz, M. W., Kuehn, P., \& Smith, K. (2003). The relationship of character education implementation and academic achievement in elementary schools. Journal of research in character education, 1(1), 19-32. 
Budimah, H., \& Rosidin, U. (2014). Pengembangan Modul Pembelajaran IPA Berbasis Karakter Materi Kalor SMP Kelas VII di Bandar Lampung. Jurnal Sains dan Pendidikan, 1(1), 1-8.

Fauzia, A. R., Yulianti, D., \& Khumaedi, K. (2017). Pengembangan Lembar Kerja Siswa (LKS) Fisika Materi Suhu dan Kalor Berbasis Learning Cycle 7E Untuk Membangun Karakter Siswa. UPEJ Unnes Physics Education Journal, 6(1), 34-43. https://doi.org/10.15294/upej.v6i1.13926

Kemendikbud. (2014). Penilaian Hasil Belajaroleh Pendidik pada Pendidikan dasar dan Menengah. Jakarta: Kemendikbud

Kemendiknas, (2011) Badan Penelitian dan Pengembangan 2011. Pedoman Pelaksanaan Pendidikan Karakter. Jakarta: Kementerian Pendidikan Nasional.

Kaleka, M., \& Ika, Y. E. (2019). Pengembangan Lembar Kerja Siswa IImu Pengetahuan Alam Berkarakter Model Inquiry untuk Siswa Kelas IX. PSEJ (Pancasakti Science Education Journal), 4(1), 1-6.

National Research Council (NRC). (1996). National Science Education Standatds. Washinton, DC: National Academy Press.

National Research Science Council (NRSC). (2000). Inquiry and the National Science Education Standards. Washinton, DC: National Akademik Press. Available http://www.nap.edu/books/0309064767/html/ . diakses tanggal 5 Januari 2018.

Permendiknas No. 22 Tahun 2006 tentang Standar Isi untuk Satuan Pendidikan Dasar dan Menengah

Puskur. 2007. Panduan Pengembangan Pembelajaran IPA Terpadu. Jakarta: Pusat Kurikulum Balitbang Depdiknas

Salis Ahda. (2016). Model Pembelajaran Inquiry Link Maps (PILM). Malang: Penerbit Universitas Negeri Malang (UM PRESS).

Sugiyono. (2010). Metode Penelitian Pendidikan Pendekatan Kuantitatif, Kualitatif, dan R\&D. Bandung: Alfabeta.

Suparno, P. (2007). Model-Model Pembelajaran. Kanisius: Yogyakarta

Suyanto, E. (2006). Penguasaan Teori dan Praktik Membuat Skenario Pembelajaran Mikro. Makalah Mata Kuliah Strategi Pembelajaran Fisika. Bandar Lampung: Universitas Lampung

Yıldırım, N., Kurt, S., \& Ayas, A. (2011). The effect of the worksheets on students' achievement in chemical equilibrium. Journal of Turkish Science Education, 8(3), 44-58. 